\title{
Inclusão escolar de alunos com deficiência intelectual e paralisia cerebral no Ensino Fundamental
}

\section{Denise Cristina da Costa França dos Santos}

Mestranda em Educação Escolar. UNESP - Universidade Estadual Paulista. Faculdade de Ciências e Letras - Pós-graduação em Educação Escolar. Araraquara-SP - Brasil. 14800-901 nise_paz@yahoo.com.br

\section{Relma Urel Carbone Carneiro}

Docente do Departamento de Psicologia da Educação e do Programa de PósGraduação em Educação Escolar. UNESP - Universidade Estadual Paulista. Faculdade de Ciências e Letras - Pós-graduação em Educação Escolar. Araraquara-SP - Brasil. 14800-901 relmaurel@fclar.unesp.br 


\section{Resumo}

Diante de políticas educacionais que retratam a importância e a legitimidade da inclusão de alunos com deficiências no ensino comum, fizemos um estudo para verificar qual a visão de um professor do Ensino Fundamental I que tem em sua sala um aluno com deficiência intelectual e uma aluna com paralisia cerebral. Para tanto, utilizamos uma pesquisa de abordagem qualitativa, para coleta de dados, utilizamos a entrevista semiestruturada. Nosso objetivo foi analisar quais concepções o professor tem de seu trabalho docente, da inclusão, do apoio da equipe gestora e do AEE, da aprendizagem dos alunos e seu contato com a família. Os resultados demonstraram que a matrícula na classe comum, muitas vezes significa uma inclusão para a socialização e que os aspectos cognitivos por vezes são deixados de lado. A inclusão é possível, mas, diz respeito à capacidade da escola de redesenhar sua cultura organizacional como um todo, de modo a atender às especificidades de cada um dos educandos, propondo e executando estratégias em favor da formação integral deles.

Palavras-chave: Inclusão Escolar. Deficiência Intelectual. Paralisia Cerebral. Ensino Fundamental I.

\section{Abstract}

Faced with educational policies that portray the importance and legitimacy of the inclusion of students with disabilities in common education, we did a study to verify the vision of a teacher of Elementary School I who has in his classroom a student with intellectual disability and a student with cerebral palsy. For that, we used a qualitative approach, for data collection, we used the semi-structured interview. Our objective was to analyze what conceptions the teacher has of his / her teaching work, the inclusion, the support of the management team and the AEE, the students' learning and their contact with the family. The results demonstrated that enrollment in the common class often means an inclusion for socialization and that cognitive aspects are sometimes left out. Inclusion is possible, but it concerns the school's ability to redesign its organizational culture as a whole, in order to meet the specificities of each of the learners, proposing and executing strategies in favor of their integral formation.

Keywords: School Inclusion. Intellectual Deficiency. Cerebral Palsy. Elementary School I. 


\section{Introdução}

Nos últimos anos, o que impulsionou a Inclusão, foi o movimento "Escola para Todos", que teve como mola propulsora a Conferência Mundial de Educação para todos, Jomtien, que ocorreu na Tailândia em 1990 (UNESCO, 1990). Decorrente dos compromissos firmados pelos governos, em 1994 ocorreu a Conferência Mundial sobre “Necessidades Educativas Especiais”, realizada pela Unesco, da qual nasce a Declaração de Salamanca (BRASIL, 1994), que proclama que as escolas comuns representam o meio mais eficaz para combater atitudes discriminatórias. Nesse contexto, o princípio norteador, é uma escola que atenda toda a diversidade presente nela e que o sistema educacional deixe de ser segregacionista e homogeneizante.

A temática da Inclusão escolar não está apenas relacionada ao campo da educação, mas faz parte de um processo mais amplo, que envolve a sociedade como um todo, já que se trata de uma reestruturação social, em âmbitos físicos e arquitetônicos, de recursos humanos, e de uma nova mentalidade, onde se crie uma cultura inclusiva no imaginário das pessoas.

Existe uma legislação e vários documentos que regem o sistema educacional, que retratam a importância e a legitimidade da inclusão de alunos com deficiências no ensino comum. Dados publicados no documento sobre a Política Nacional da Educação Inclusiva (BRASIL, 2007) demonstram, entre outros, que no sistema educacional, entre os anos de 1998 - 2006 houve um aumento do número de alunos incluídos em classes comuns do ensino regular, passando de 43.923 alunos em 1998, para 325.136 em 2006, crescendo 640\%. Esses dados demonstram que a educação inclusiva está se efetivando no sistema educacional brasileiro, no que diz respeito ao acesso de alunos com deficiências no sistema regular de ensino, mas como de fato esse processo está ocorrendo?

O Brasil é um país de muitas leis, e elas despertam as pessoas e as sensibilizam para algo considerado necessário, nesse caso em específico, quanto à concepção de que, de fato, a educação é um direito de todo cidadão. É a lei que nos garante direitos. E a inclusão é uma maneira de garantir que os alunos que tiveram negada durante anos sua escolarização em espaços comuns, agora estejam na rede regular de ensino.

Reconhece-se que o legítimo papel da escola é a transmissão do saber adquirido socialmente e historicamente. Portanto, não basta que os alunos estejam na sala de aula, 
é necessário que tenham acesso ao conhecimento. Somente as leis não garantem a inclusão, pois elas não eliminam estereótipos e preconceitos arraigados. Carvalho (2004, p.26) nos diz que a noção de escola inclusiva implica, indubitavelmente, na mudança de atitudes frente às diferenças individuais e coloca: "Escolas inclusivas são escolas para todos, implicando num sistema educacional que reconheça e atenda às diferenças individuais, respeitando as necessidades de qualquer dos alunos".

O ensino fundamental é uma etapa do ensino que tem grandes desafios em relação à inclusão, já que se tem muitos conteúdos curriculares, os alunos são todos agrupados por idade série, como se a mesma idade garantisse o mesmo conhecimento. Sobre isto, Mantoan (2003, p.40), afirma:

\footnotetext{
Não se pode imaginar uma educação para todos, quando caímos na tentação de constituir grupos de alunos por séries, por níveis de desempenho escolar e determinamos objetivos para cada nível. E, mais ainda, quando encaminhamos os que não cabem em nenhuma desses grupos para classes e escolas especiais, argumentando que o ensino para todos não sofreria distorções de sentido em casos como esses!
}

Há muitos posicionamentos e vários debates acerca da inclusão de pessoas com deficiências na rede regular de ensino, sobretudo entre os professores, que ao receberem esses alunos, se sentem inseguros e perdidos em como trabalhar com eles. Presumindo esse cenário, realizou-se uma entrevista como parte de um trabalho maior de outras entrevistas, no intuito de perceber quais as concepções do professor acerca do trabalho docente, da inclusão, da aprendizagem dos alunos, do apoio dos gestores e do AEE, e seu contato com os familiares.

\section{Método}

Tendo em vista o objeto desse estudo, a pesquisa se insere em uma abordagem qualitativa. Conforme Minayo (2002, p. 21-22), esse tipo de pesquisa se preocupa com um nível de realidade que não pode ser quantificado, nem reduzido à operacionalização de variáveis, pois abrange o universo dos significados, motivos, aspirações, crenças, valores e atitudes dos indivíduos sobre determinado fenômeno. Para Lüdke \& André (1986, p. 18), o estudo qualitativo “(...) se desenvolve numa situação natural, é rico em 
dados descritivos, tem um plano aberto e flexível e focaliza a realidade de forma complexa e contextualizada". Com base nesses pressupostos metodológicos, uma professora de uma escola da rede pública de uma cidade do interior de SP, que tinha em sua sala de aula dois alunos com deficiências foi selecionada. A professora entrevistada tinha 33 anos, atuava no Ensino Fundamental I, com alunos do $5^{\circ}$ ano. Sua formação acadêmica se deu no ensino Médio Comum e seguiu para o Curso Superior de Pedagogia, que concluiu em 2009. Não tinha pós- graduação. Ela tinha na sala no ano letivo em questão, um aluno diagnosticado com Deficiência Intelectual Moderada e um com Paralisia Cerebral. Quanto ao tempo de magistério, exerce a profissão há cinco anos. Quanto ao tempo de atuação junto aos educandos com deficiências, essa é sua primeira experiência.

$\mathrm{O}$ instrumento de coleta de dados foi uma entrevista semiestruturada. Segundo Minayo (2002), a entrevista representa um instrumento que tem o propósito de "dar voz" ao entrevistado, no sentido de conhecer o que ele tem a dizer acerca da temática evidenciada. A análise e a interpretação dos dados coletados foram organizados a partir da técnica de Análise de Conteúdo, que segundo Bardin (2009) se organiza em três fases: 1) pré-análise, 2) exploração do material e 3) tratamento dos resultados, inferência e interpretação.

\section{Resultados e Discussão}

Algumas respostas da entrevista revelam um modo de ser professora, que implica na obrigação de trabalhar com alunos com deficiência. A visão de que a inclusão é algo imposto e não fruto de escolha, contribui para o fracasso escolar de alguns alunos e o adoecimento de alguns professores. Para uma análise mais completa do conteúdo da entrevista, foram criadas categorias de análise e são: Concepção da profissão docente, Concepção de inclusão, Trabalho Colaborativo por parte da equipe gestora e do atendimento educacional especializado - AEE, Concepção de aprendizagem do aluno com deficiência, Contato com a família. A partir da análise de trechos da fala da professora e pudemos fazer alguns paralelos com o que alguns autores dizem a respeito do tema, confrontando ou integrando a literatura com a realidade. 


\section{Concepção da Profissão Docente}

A primeira questão da entrevista tinha o objetivo de apreender o significado da profissão para a docente. Tivemos a seguinte resposta:

Ser professor é poder contribuir com a formação do aluno, é instigar a reflexão, é possibilitar a aprendizagem, é mediar os conflitos internos e externos à escola, é ouvir e atender a necessidade do aluno. É estar atento as questôes sociais deles, e dar ferramentas para que ele possa mudar.

De acordo com a resposta, podemos inferir que essa professora está preocupada em não ser apenas uma transmissora de conhecimentos, mas, de formar integralmente esse aluno. Para Freire (1998) Ser professor, implica em um compromisso constante com as práticas sociais.

\section{Concepção de Inclusão}

$\mathrm{Na}$ segunda categoria destaca-se a concepção da professora a respeito da inclusão de seus alunos (um com Deficiência Intelectual Moderada e uma com Paralisia Cerebral) e da inclusão como um todo.

Podemos destacar as seguintes passagens:

Quando peguei essa turma já sabia da aluna com Paralisia Cerebral, mas, até ai foi tranquilo, porque sabia que o problema dela era apenas motor. Mas, na terceira semana de aula, recebi o aluno com deficiência Intelectual, ai fiquei preocupada. Sem saber o que fazer. Porque percebi que ele era muito comprometido psicologicamente e fiquei pensando o que eu iria fazer para que ele aprendesse. Ainda mais que é um quinto ano, tem muito conteúdo e difícil.

Gostaria muito que a inclusão fosse para todos, o Brasil é um país muito rico e poderia investir mais e melhor na educação e em tantas outras áreas. Mas, infelizmente vejo que como está sendo feita, apenas alguns, os mais "adaptáveis" é que são incluidos de verdade. Ainda continua em cima do que - aluno consegue para se incluir. Quando na verdade, nós que deveríamos dar condiçôes para ele. Muito triste, mas, penso que alunos com deficiência severa precisam estar em escolas especializadas, porque lá terão melhores condiçóes e atendimentos do que na sala comum. Precisamos de turmas mais parecidas, para que consigamos ensinar de verdade. Quando há muita 
discrepância fica difícil. Quem sabe um dia, tenhamos mais profissionais da educação e da saúde, na escola pública e ai sim, possamos incluir todos.

Sempre fui a favor da inclusão. Até nesse ano receber esses dois alunos. Continuo sendo a favor, em alguns casos eu ainda continuo pensando que é possivel, mas, nos casos graves, mais severos, vai ter a inclusão social, mas não a aprendizagem.

Analisando a resposta da professora é possível perceber que para ela a inclusão é possível, dependendo da necessidade do aluno. Mas, independente do tipo de deficiência, todos tem o direito, é para todos, e a escola deve receber e atender qualquer demanda. Como nos diz Perrenoud (2000, p. 10)

[...] apesar dessas evidências e das análises progressivamente mais precisas da fabricação das desigualdades e do fracasso a partir dos anos 60, o modo dominante de organização da escolaridade não mudou muito: agrupam-se os alunos conforme a sua idade (que presumidamente indica o nível de desenvolvimento) e os seus conhecimentos escolares, em 'turmas que falsamente se crê serem homogêneas o suficiente para que cada um tenha chance de assimilar o mesmo programa durante o mesmo tempo.

Essa manifestação permite dizer que, essa professora acredita numa turma homogênea, onde todos os alunos teriam as mesmas condições para aprender, perpassa o imaginário, que a inclusão depende do tipo de deficiência, e que casos mais graves, não podem ser incluídos. De acordo com análises de Dall'Acqua e Vitaliano (2010, p. 25) “a escola se organizou historicamente para ser indiferente às diferenças, com práticas homogêneas e excludentes que se distanciam das propostas destinadas as escolas inclusivas". Para ser inclusiva de fato, precisa atender a todos indistintamente.

A inclusão é justificada em argumentos que fundamentam o direito de todos independente da natureza e severidade de suas deficiências, de estarem em salas regulares, ambiente considerado próprio pensando que os alunos com deficiência teriam acesso aos conteúdos desejáveis para a sua idade e os ditos normais teriam a oportunidade de se libertarem de ideias preconceituosas que se perpetuam por anos a fio (STAINBACK; STAINBACK,1999). 


\section{Trabalho Colaborativo por parte da equipe gestora e do AEE}

Quando questionada se teve apoio da equipe gestora ou do AEE, infelizmente a resposta é negativa. Vamos analisar as respostas, partindo de como a professora soube que teria alunos com deficiência, passando pelas adaptações que seriam necessárias e pelo apoio cotidiano em sua sala. Alguns fragmentos das respostas:

A secretária da escola chegou com ele na minha sala, juntamente com sua mãe e disse: Como sua sala estava com menos aluno, esse é o aluno que chegou e veio pra você, ele é da inclusão. Tem Deficiência Mental. Ai fui receptiva com ele e sua mãe, perguntando seu nome, e dizendo que ele era bem vindo. Mas, no fundo, estava pensando o que faria? Já tenho 29 alunos, mais a menina com PC e agora um menino com DM?

Que nada! Apoio nenhum. Na sala de aula as estratégias que busquei foi sozinha mesmo. Fui atrás de ler e conhecer certinho as deficiências e quais eram as necessidades desses meus alunos. Preparar aulas diferenciadas para 0 aluno com DM. Para a aluna com PC não precisou de muita coisa, só algumas adaptaçóes físicas, da cadeira que ela precisava pra sentar, e também do lápis que era mais grosso, das colheres que ela usava pra comer, até isso eu adaptei, porque ninguém fazia nada.

Percebemos nessa fala que nessa escola o que se chama de inclusão está acontecendo por ela só, já que a gestão escolar e os elementos da organização escolar se mantêm longe de mudanças, não há uma real preocupação a fim de receber e atender todos os alunos em sua especificidade.

Para o aluno com DM, ele tem muito comprometimento cognitivo, tenho que fazer adaptaçóes de conteúdo o tempo todo. Na verdade, quando consigo, faço um trabalho de alfabetização com ele, enquanto que com os demais dou o conteúdo do $5^{\circ}$ ano. Já com a aluna com PC, fiz apenas adaptaçóes físicas, porque seu cognitivo é extremamente preservado.

Muitos alunos e não somente os com deficiência necessitam de um ensino diferenciado, torná-lo pois diferenciado é,

[...] fazer com que cada aprendiz vivencie, tão frequentemente quanto possível, situações fecundas de aprendizagem. Para executar essa ideia 
simples é preciso mudar profundamente a escola. Acrescentemos de imediato que adaptar a ação pedagógica ao aprendiz não é, no entanto, nem renunciar a instruí-lo, nem abdicar dos objetivos essenciais. Diferenciar é, pois, lutar para que as desigualdades diante da escola atenuem-se e, simultaneamente, para que o nível de ensino se eleve (PERRENOUD, 2000, p. 9).

O ensino diferenciado é o começo para um trabalho mais responsável e sério, que almeje a aprendizagem dos alunos.

\begin{abstract}
$A$ aluna com $P C$ não faz o AEE. Já o aluno com $D M$, vem no horário contrário, para o atendimento. Um dia no HTPC, pedi pra falar com a professora do AEE, já que não me sinto preparada para o trabalho com o aluno com DM. Ela não se mostrou muito interessada, mas, veio. Ai falei pra ela que estava alfabetizando esse aluno. Ela me interrompeu e disse para eu ficar tranquila que ela sabia trabalhar melhor que eu as deficiências. Ai expliquei que tinha pensado em trabalharmos juntas, pra ver se os resultados seriam melhores. Mas ela nem deu atenção.
\end{abstract}

Geralmente os professores da sala regular se sentem menos preparados do que os especializados. E com posturas como essa, do professor do AEE, o trabalho docente fica esfacelado.

Os professores do ensino regular consideram-se incompetentes para lidar com as diferenças nas salas de aula, especialmente atender os alunos com deficiência, pois seus colegas especializados sempre se distinguiram por realizar unicamente esse atendimento e exageraram essa capacidade de fazê- lo aos olhos de todos (MITTLER, 2000).

\title{
Concepção de aprendizagem dos alunos com deficiência
}

Quando questionada sobre a aprendizagem dos alunos, os fragmentos são:

A aluna com PC tranquilo, ela acompanha super bem os conteúdos. Agora do aluno com DM, não, a aprendizagem dele não é satisfatória. Por dois motivos, primeiro porque ele precisa de alguém mais tempo presente ao lado dele, e eu não dou conta. Depois porque ele tem muitas limitações cognitivas mesmo. 
É possível perceber nessa fala que esse aluno está incluído fisicamente, mas, suas aprendizagens cognitivas não estão sendo garantidas. A deficiência intelectual desestrutura a organização comum da escola, que segue um padrão de homogeneidade e desconsiderada qualquer outra forma de lidar com o conhecimento. A inclusão de estudantes com deficiência intelectual pressupõe uma nova forma de conceber os processos de ensino-aprendizagem, considerando o acesso e a produção do conhecimento a partir de parâmetros individuais.

Quando questionada sobre a interação dos alunos com deficiência com os demais, temos a seguinte resposta:

\footnotetext{
Nisso sim considero a inclusão válida. A interação dos alunos é ótima. Os demais da classe acolberam muito bem os alunos com Deficiência. É bom para ambos. Os da inclusão por estarem num ambiente mais ampliado, com mais pessoas, diversidade. E para os demais, exercitam a paciência, a solidariedade. Nesse aspecto a inclusão acontece verdadeiramente.
}

Evidencia-se na resposta que o principal avanço trazido pela inclusão de alunos com deficiência no ensino regular diz respeito à socialização dos mesmos. Durante a entrevista foi possível perceber que se dá muito valor à socialização, deixando transparecer, que os elementos cognitivos estão sendo deixados à margem, ou que no muito se garantirá um pouquinho, já que o aluno é visto com capacidade cognitiva muito inferior.

\section{Contato com a família}

$\mathrm{Na}$ última categoria de análise, tínhamos a intenção de apreender a relação da escola com a família, já que consideramos ser elemento fundamental na aprendizagem dos alunos.

Da aluna com $P C$, tenho bastante contato com a familia. Eles vêm trazer e buscar ela, então sempre nos falamos na porta da sala. São pais bem presentes. Já do aluno com DM, vi seus pais apenas uma vez na reunião que convoquei. O aluno frequenta a APAE, e chega na escola, no ônibus que vem de lá. A familia tem poucas condiçôes financeiras. Ambos os pais são trabalhadores rurais. Tem uma vida extremamente difícil. Não são alfabetizados. Tentam cuidar da bigiene e da alimentação do filho, mas, infelizmente no quesito cognitivo, falam que não têm condições de ajudar. 
Tenho muita pena dessa família. E por isso tento cumprir meu papel de professora, quero muito alfabetizar esse aluno.

Através da fala é possível perceber que uma das famílias é mais presente, já a outra, do aluno com DI, percebe-se condições bem precárias de vida, o que dificulta o contato entre a escola e a família, na fala da professora e certamente interfere no processo de desenvolvimento do aluno.

\section{Conclusão}

Os dados apresentados mostram uma realidade em que professores "querem" fazer diferença, na medida em que procuram se apropriar da nova situação que se apresenta, conhecer sobre a deficiência que seu aluno possui, buscar meios e estratégias para que esse aluno aprenda e, por outro lado, a grande dificuldade em dar conta de atender a diversidade presente na sala de aula. Nos parece claro, que a vigência de leis que preconizam a inclusão, por si só, não vão garantir totalmente a efetivação desse projeto na prática, que pressupõe uma mudança de paradigma com a modificação de várias estruturas como a física, a atitudinal, a instrumental, entre outras.

Estudos têm mostrado que o tipo de deficiência também interfere nas atitudes sociais dos professores em relação à inclusão dos alunos. Artiolli (1999) evidenciou que os professores do ensino comum previram dificuldade menor para a inclusão de alunos com deficiência física do que os alunos com deficiência auditiva, intelectual ou visual. Balboni e Pedrabissi (2000) também concluíram que são mais positivas as atitudes sociais em relação à inclusão de alunos com problemas de aprendizagem ou deficiência física do que as atitudes em relação à inclusão de alunos que têm problemas emocionais ou comportamentais e alunos com deficiência intelectual.

Foi possível perceber através da entrevista que essa professora não se opõe à inclusão escolar, apenas não se sente totalmente preparada para lidar com as várias questões que envolvem a efetivação da mesma. Talvez um aliado para resolver esse desafio seja a formação continuada. Já que ela pode ajudar na construção de novos saberes, na troca de experiências, no acesso ao que tem dado certo no âmbito da sala de aula para o trabalho com a inclusão. 
São inúmeros os desafios para todos, especialmente para o professor. É possível perceber que cada um concebe subjetivamente a imagem que tem frente à deficiência e a inclusão, e isso é permeado por valores socioculturais, isso significa que cada professor vê e atribui significados diferentes na inclusão de seus alunos. Mentalidades e atitudes positivas quanto a uma sociedade inclusiva, a tornará inclusiva de fato, e o oposto também é verdadeiro: atitudes negativas prejudicam. No tocante à escola, Bender, Scott e Vail (1995) evidenciaram que os professores do ensino comum com atitudes negativas em relação à inclusão utilizavam estratégias de ensino inclusivas menos frequentemente que os professores com atitudes positivas. Certamente as atitudes sociais são fundamentais na implementação de uma sociedade e de uma escola inclusiva.

Um dos desafios a ser enfrentado pelo paradigma inclusivo se refere à organização dos espaços. Segundo Padilha (1997, p.96),

\begin{abstract}
Colocar todas as crianças juntas, em um mesmo lugar, em um mesmo tempo para aprender tudo não significa que todas aprenderão o que realmente precisam aprender. Juntar crianças em uma sala de aula não lhes garante ensino, não lhes garante escola cumprindo seu papel, não lhes garante aprendizagem e, portanto, não lhes garante desenvolvimento. Deixar crianças e jovens deficientes ou pobres sem escola, sem ensino, sem aprendizagem e abandonados à própria sorte é impedir, de forma violenta, o exercício do direito que todos têm de participar dos bens culturais produzidos pela humanidade. [...] Igualmente violento é deixá-los na escola, matriculados, com lugar marcado na sala de aula, mas sem aprender, sem o acesso a todos os instrumentos e estratégias que respondam às suas necessidades peculiares.
\end{abstract}

Para que a escola seja de fato inclusiva, é necessário um novo olhar, um refazerse. Os alunos precisam ser respeitados em suas singularidades. $\mathrm{O}$ acesso a todas as séries do ensino fundamental (obrigatório) deve ser incondicionalmente garantido a todos. $\mathrm{E}$ para que isso ocorra faz-se necessária uma reformulação de mentalidades, de mudanças ao planejar, executar e avaliar os processos educativos. Segundo as análises de Glat (2007, p. 16):

A educação inclusiva significa um novo modelo de escola em que é possível o acesso e a permanência de todos os alunos, e onde os mecanismos de seleção e discriminação, até então utilizados, são substituídos por procedimentos de identificação e remoção das 


\begin{abstract}
barreiras para a aprendizagem. Para tornar-se inclusiva a escola precisa formar seus professores e equipe de gestão, e rever formas de interação vigentes entre todos os segmentos que a compõem e que nela interferem, precisa realimentar sua estrutura, organização, seu projeto político pedagógico, seus recursos didáticos, metodologias e estratégias de ensino, bem como suas práticas avaliativas. A proposta de educação inclusiva implica, portanto, um processo de reestruturação de todos os aspectos constitutivos da escola, envolvendo a gestão de cada unidade e os próprios sistemas educacionais.
\end{abstract}

Conclui-se, que a inclusão diz respeito à capacidade da escola de redesenhar sua cultura organizacional como um todo, de modo a atender às especificidades de cada um dos educandos, propondo e executando estratégias em favor da formação integral deles. É preciso estar aberto e disposto à mudanças, é ainda imprescindível reconhecer que será mais trabalhoso e que demandará mais tempo para que se transforme essa realidade.

\title{
Referências
}

ARTIOLI, A. L. A integração do aluno deficiente na classe comum: o ponto de vista do professor. 1999. Dissertação (Mestrado em Educação), Universidade Estadual Paulista, Marília, 1999.

BALBONI, G.; PEDRABISSI, L. Attitudes of Italian teachers and parents toward school inclusion of students with mental retardation: the role of experience. Education and Training em Mental Retardation and Developmental Disabilities, v. 35, n. 2, p. 148$159,2000$.

BARDIN, L. Análise de Conteúdo. Lisboa, Portugal; Edições 70, LDA, 2009.

BRASIL, Ministério da Ação Social. Coordenadoria Nacional Para Integração da Pessoa Portadora de Deficiência. Declaração de Salamanca e linha de ação sobre necessidades educativas especiais. Brasília: MAS/ CORDE, 1994.

BRASIL, Ministério da Educação. Politica Nacional de Educação Especial na Perspectiva da Educação Inclusiva. 2007. Disponível em:

http://portal.mec.gov.br/arquivos/pdf/politicaeducespecial.pdf. Acesso em: 03 de Outubro de 2017. 
BENDER, W. N.; SCOTT, K.; VAIL, C. O. Teachers' attitudes toward increased mainstreaming: Implementing efective instruction for students with learning disabilities. Journal of Learning Disabilities, v. 28, p. 87-94, 1995.

CARVALHO, R.E. Educação Inclusiva: com os pingos nos “is”. Porto Alegre: Mediação, 2004.

DALL'ACQUA, M. J. C.; VITALIANO, C. R. Algumas reflexões sobre o processo de inclusão dêem nosso contexto educacional. In: VITALIANO (org). Formação de professores para a inclusão de alunos com necessidades educacionais especiais. Londrina: EDUEL, 2010.

GLAT, R. (Org.) Educação Inclusiva: cultura e cotidiano escolar. Rio de Janeiro: 7 Letras, 2007.

LUDKE, M.; ANDRÉ, M. E. D. A. Pesquisa em educação: abordagens qualitativas. São Paulo, E.P.U., 1986. 99p.

MANTOAN, M.T,E. Inclusão escolar: o que é? por quê? como fazer? São Paulo: Moderna,2003. Coleção cotidiano escolar.

MINAYO, M. C. Pesquisa Social: teoria, método e criatividade. Petrópolis, Vozes, 2002.

MITTLER, P. Working towards inclusion education: social contexts. London, David Fulton Publishers Ltd., 2000.

PADILHA, A. M. L. Possibilidades de bistórias ao contrário: ou como desencaminhar o aluno da classe especial. São Paulo: Plexus, 1997.

PERRENOUD, P. Pedagogia diferenciada: das intenções à ação. Porto Alegre: ARTMED, 2000.

STAINBACK, S. B.; STAINBACK, W.C. Inclusão: um guia para educadores. Porto Alegre: Artmed, 1999. (129-141). 
SANTOS, D. C. da C. F. dos; CARNEIRO, R. U. C. Inclusão escolar de alunos com deficiência intelectual e paralisia cerebral no Ensino Fundamental I. R. Cientifica UBM - Barra Mansa (RJ), ano XXII, v. 19, n. 37, 2. Sem. 2017. p. 170-184.

ISSN 1516-4071

UNESCO- Organizações das Nações Unidas para a Educação, Ciência e Cultura. Declaraşão Mundial sobre Educação Para Todos (Conferência de Jomtien). Tailândia: Unesco, 1990. Disponível em:

http://unesdoc.unesco.org/images/0008/000862/086291por.pdf. Acesso em 03 de Outubro de 2017. 